\title{
Association between antenatal steroids for lung maturation and hypoglycaemia in the first 48 hours in premature infants between 26 and 34 weeks of gestational age
}

Związek pomiędzy prenatalnym leczeniem dojrzewania płuc steroidami a hipoglikemią w ciągu pierwszych 48 godzin życia u wcześniaków urodzonych pomiędzy 26. a 34. tygodniem ciąży

\section{Gina M. González Valencia, Victor C. Mendoza Rojas}

Pediatric Department, Industrial University of Santander, University Hospital of Santander, Colombia

The research was presented in poster mode at the European Congress of Paediatric Endocrinology in 2018.

\begin{abstract}
Introduction: Hypoglycaemia is frequent in premature infants and can generate neurological alterations. There is controversy concerning exposure to antenatal corticosteroids for pulmonary maturation and hypoglycaemia.

Aim of the study: To evaluate whether there is a relationship between neonatal hypoglycaemia and the use of antenatal corticosteroids for lung maturation in preterm infants between 26 and 34 weeks of gestational age, and to correlate this with other variables. Material and methods: A prospective closed cohort study in preterm infants between 26 and 34 weeks of gestation, who were born in the University Hospital of Santander (HUS) between 2017 and 2018, divided into two cohorts: exposed and not exposed to antenatal corticosteroids for lung maturation. The data was analysed using Stata 12.0 Software.

Results: Of 173 preterm infants, $152(87.9 \%)$ received lung maturation. There were no significant differences between the maternal characteristics of both cohorts. In the neonatal group, sex, gestational age, birth weight, Apgar score, and glucose infusion rate were evaluated without significant differences. The cumulative incidence of hypoglycaemia in the first 48 hours was $28.6 \%$ in those not exposed to antenatal corticosteroids and 25.4\% among the exposed ones (RR 0.875, IC95\% 0.421-1.815), while the incidence density of hypoglycaemia was 8.80 and 6.36 events/1000 person-hours, respectively (HR $0.74395 \% \mathrm{Cl}: 0.314-1.759$ ).

Conclusions: There was no significant difference in the incidence of hypoglycaemia among those exposed and those not exposed to antenatal steroids for lung maturation in this study.

Key words:

infant, premature, hypoglycaemia, steroids.
\end{abstract}




\section{Introduction}

Hypoglycaemia is a frequent condition in neonatal care units, and its importance lies in its relationship with alterations in neurodevelopment [1-6]. The values defining it are still controversial, with the definitions proposed by the Paediatric Endocrinology Society and by the American Academy of Paediatrics being the most used [7-10]. The maternal risk factors which may trigger it include, among others: gestational diabetes, maternal obesity, the use of beta-blockers or hypoglycaemic agents, and associated hypertensive disorders in pregnancy $[1,3,11,12]$. Neonatal risk factors include low weight, intrauterine growth restrictions, small foetus for gestational age, prematurity, infections, respiratory distress syndrome, or inborn errors of metabolism, among others [3, 9, 12-14].

The benefits of the use of maternal prenatal steroids in preterm infants are well documented; with a decrease in the incidence of respiratory distress syndrome, necrotising enterocolitis, periventricular leukomalacia, or persistent ductus arteriosus, among others, as well as lower mortality and hospitalisation time [15-19]. However, other publications find side effects of the use of prenatal steroids, especially from multiple cycles: Bevilacqua et al., in their meta-analysis published in 2010, reported lower foetal weight and lower cephalic circumference, findings that were also described in other publications $[15,18,20]$. In turn, Mazunder et al. reported shorter stature at six months of postnatal life [16].

On the other hand, Gyamfi-Bannerman et al. reported that when applying antenatal corticosteroids between weeks 34 and 36 of gestation, newborns improved respiratory outcomes, although they presented a greater number of instances of hypoglycaemia in patients exposed to betamethasone [21], Alrais et al. indicated a higher frequency of admission to neonatal intensive care secondary to low glucose values among preterm infants exposed to the steroid prenatally but without finding significant differences related to the length of stay in the unit [22]. In contrast, studies by Koivisto et al. and Pettit et al. did not describe this association [23, 24].

\section{Aim of the study}

This study seeks to evaluate whether there is a relationship between the incidence of neonatal hypoglycaemia and the use of antenatal corticosteroids for lung maturation in preterm infants between 26 and 34 weeks of gestational age.

\section{Material and methods}

This is a prospective closed-cohort study. The procedures followed the principles of the Declaration of Helsinki. The Ethics Committees of the University Hospital of Santander (HUS) and the Industrial University of Santander endorsed the protocol.

Neonates between 26 and 34 weeks of gestational age, born at the HUS, Colombia between 2016 and 2017 were ana- lysed. They were divided into two cohorts: one to those exposed to antenatal betamethasone for lung maturation and one another to those who were not exposed. Neonates with identifiable genetic syndromes, adrenal insufficiency, suspicion of multiple deficit of pituitary hormones, and those exposed to steroids for causes other than lung maturation were excluded. Those for whom data collection was incomplete were also excluded. The data was obtained from the medical records of the newborns. When there was missing information, it was checked directly with the mother or with the manual nursing records. The main outcome was the presence in the first 48 hours of hypoglycaemia according to the parameters of the Paediatric Endocrine Society (central glucose or capillary glucose $<50 \mathrm{mg} / \mathrm{dl}$ ). The recollection of the information finished when the neonates complete 48 hours of life or when an episode of hypoglycaemia was identified during that period of time.

Variables were analysed in proportions or measures of central tendency and dispersion, according to their nature. Differences were established between the two cohorts using the chisquare test or Mann-Whitney $U$ test, considering the value of $p<0.05$ as significant. The overall incidence was calculated for each cohort with their respective 95\% confidence intervals. Two multivariate models were performed: in the first, binomial regression was performed to estimate the relative risk (RR) of hypoglycaemia; in the second, a Cox model was proposed for estimating the difference in the two cohorts in terms of incidence density. In both, the assumptions of the model were verified. Finally, Kaplan-Meier hypoglycaemia-free survival curves were explored, including whether there were differences in the incidence of hypoglycaemia according to maternal age and primiparity.

\section{Results}

Of 3480 infants born alive in the HUS during the collection period, 173 fulfilled the inclusion criteria, 152 (87.9\%) of whom received pulmonary maturation treatment. The median maternal age was 24 years for both cohorts, with six (28.6\%) and 52 $(34.1 \%)$ among those not exposed and exposed, respectively $(p=0.608)$. No significant differences were found when performing the analysis of maternal comorbidities between the two cohorts (Table I). The median gestational age of the newborns was 33 weeks for both cohorts $(p=0.301)$. In exposed infants, the distribution by sex was 76 women (50.3\%) versus 11 women $(52.4 \%)$ in the unexposed, and the median birth weight was $1910 \mathrm{~g}$ and $1725 \mathrm{~g}(p=0.730)$, respectively. There were no significant differences when comparing Apgar score and glucose infusion rate (Table I).

The incidence of hypoglycaemia in the first 48 hours was 29 episodes per 100 newborns not exposed to antenatal steroids and 25 episodes per 100 newborns exposed to it $(p=0.725)$. The presentation speed was 8.80 and 6.36 events/1000 personhours, respectively, a difference that is not statistically significant either $(p=0.468)$. No significant differences were found according to the time in which they were exposed (two hours before birth or more hours), gestational age, weight, and number of 
doses of the steroid. There was no significant difference in the incidence of hypoglycaemia with respect to gestational age, weight, time of steroid application, and betamethasone cycles.

The binomial model indicated that exposure to foetal lung maturation with steroids was not associated with hypoglycaemia in newborns (RR 0.852, 95\% Cl: 0.411-1.771), value adjusted for maternal age, primiparity, maternal diabetes, and gestational age. The same phenomenon occurred with the Cox model, where the hazard ratio (HR) was 0.721 (95\% Cl: 0.310-1.710).

The analysis of survival revealed that the onset speed of hypoglycaemia is higher in the first 8.8 hours of life; but there are no differences between those who did or did not receive the prenatal steroids even after adjusting the data for maternal age and primiparity (Figure 1A). A higher rate of hypoglycaemia was found in the offspring of women older than 35 years of age with respect to the offspring of women aged 35 years or younger, as well as among primiparous women (Figure 1B, C). However, the binomial or Cox models did not support this finding, either for those older than 35 years (RR $1.323,95 \% \mathrm{Cl}$ : 0.585-2.992, HR 1.198, 95\% Cl: 0.472-3.039) or for primiparous women (RR 1.439, 95\% Cl: 0.847-0.2444; HR 1.456, 95\% Cl: 0.799-2.659).

Table I. Demographic characteristics of the population

\begin{tabular}{|c|c|c|c|}
\hline & \multicolumn{2}{|c|}{ Antenatal exposure to steroids } & \multirow[t]{2}{*}{$p$} \\
\hline & no $(n=21)$ & yes $(n=152)$ & \\
\hline \multicolumn{4}{|l|}{ Maternal variables } \\
\hline Maternal age (years) * & $24(20-28)$ & $24(20-30)$ & 0.459 \\
\hline Primiparity & $6(28.6 \%)$ & $52(34.1 \%)$ & 0.608 \\
\hline Maternal hypertensive disorders & $5(23.8 \%)$ & 47 (30.9\%) & 0.505 \\
\hline Gestational diabetes & $1(4.8 \%)$ & $13(8.5 \%)$ & 0.550 \\
\hline Preterm labour & $13(61.9 \%)$ & $84(55.3 \%)$ & 0.565 \\
\hline PROM & $6(28.6 \%)$ & $46(30.3 \%)$ & 0.874 \\
\hline Chorioamnionitis & $2(9.5 \%)$ & $18(11.8 \%)$ & 0.755 \\
\hline Other infections & $9(42.9 \%)$ & $52(34.2 \%)$ & 0.437 \\
\hline Twin pregnancy & $2(9.5 \%)$ & $38(25 \%)$ & 0.115 \\
\hline Gestational age (weeks) * & $33.0(31.0-34.0)$ & $33.0(31.3-34.0)$ & 0.301 \\
\hline \multicolumn{4}{|l|}{ Neonatal variables } \\
\hline Female sex & $11(52.4 \%)$ & $76(50.3 \%)$ & 0.860 \\
\hline Birth weight $(\mathrm{gr})$ * & $1725(1540-2180)$ & 1910 (1457-2222) & 0.730 \\
\hline Birth weight & $4(19.1 \%)$ & $21(13.8 \%)$ & 0.766 \\
\hline Low & $17(80.9 \%)$ & $130(85.5 \%)$ & \\
\hline Adequate & - & $1(0.7 \%)$ & \\
\hline Respiratory distress syndrome and respiratory syndromes & $18(85.7 \%)$ & $144(94.7 \%)$ & 0.112 \\
\hline Apgar 1 minute $<7$ & $10(47.6 \%)$ & $55(36.2 \%)$ & 0.310 \\
\hline Apgar 5 minutes $<7$ & $2(9.52 \%)$ & $10(6.58 \%)$ & 0.619 \\
\hline Glucose infusion rate (mg/kg/min) & $6.17(6.10-6.20)$ & $6.18(5.75-6.24)$ & 0.696 \\
\hline
\end{tabular}

PROM - premature rupture of membranes

* Median and interquartile range 
A

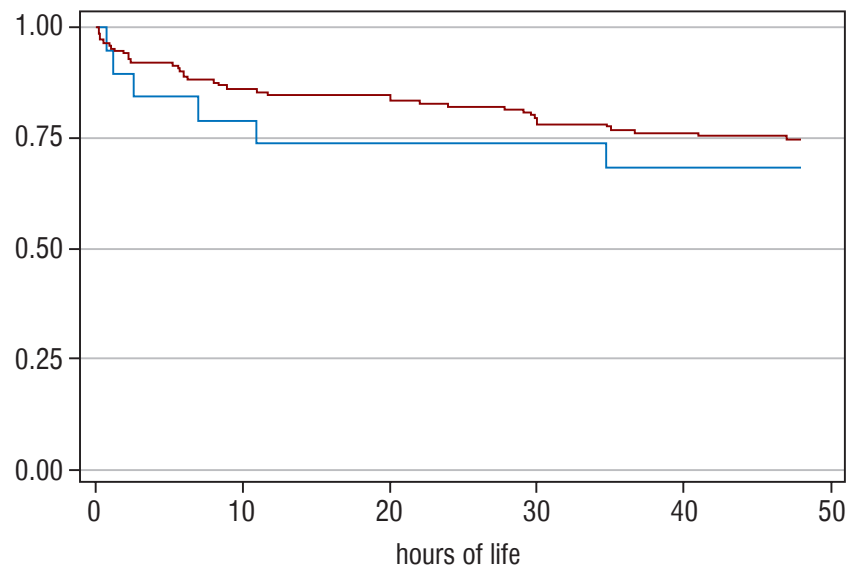

- unexposed

C

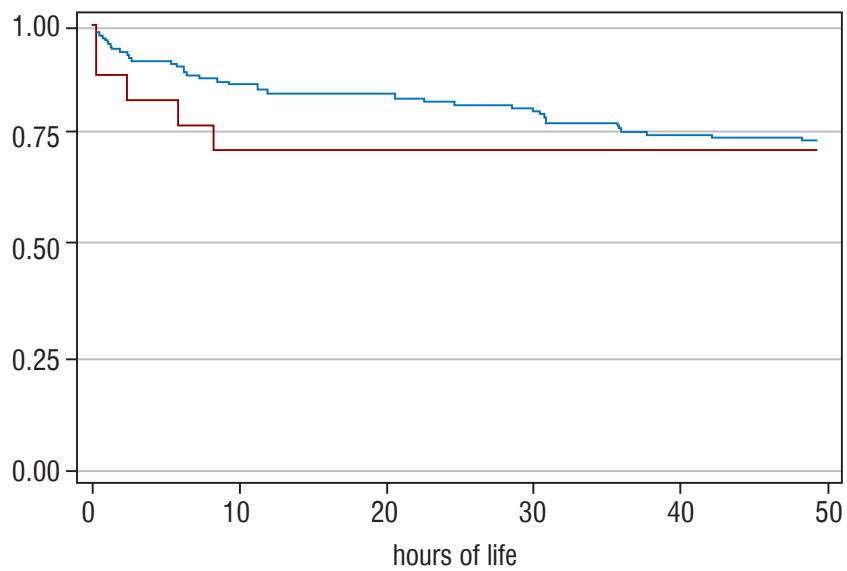

maternal age $\quad<35$ years $\quad-\geq 35$ years

\section{Discussion}

The general incidence of hypoglycaemia in preterm infants exposed to antenatal steroids was $25 \%$, with no significant differences between exposed with those unexposed. This incidence is within the ranges already reported in the literature and varies according to the reference values used, the additional risk factors of the newborn (being higher in those small for gestational age), and adherence to local guidelines [14, 25-28].

Kuper et al. [28] published a study in 2018 in which they evaluated the incidence of hypoglycaemia in neonates whose mothers did or did not receive antenatal steroids, in an age range similar to that used in this study (23 to 34 weeks of gestational age). They included 635 patients, of whom an incidence was reported in the first 48 hours of life of $23.0 \%$ (exposed) versus $16.1 \%$ (not exposed), without this difference being significant (OR 1.3, 95\% Cl: 0.5-3.6), as was found in the present study.
B

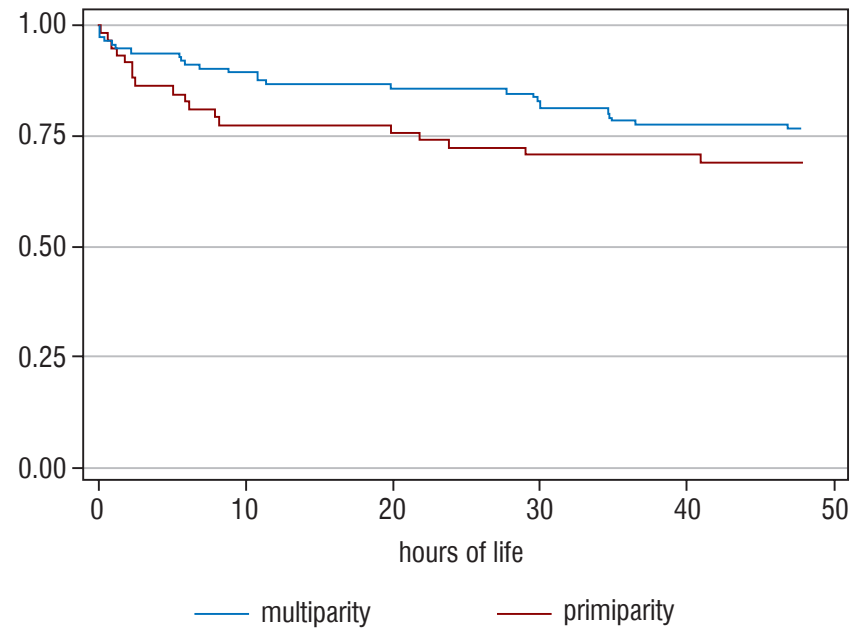

Figure 1A-C. Kaplan Meier Survival free curves of hypoglycemia among neonates acording to: A) exposed and not exposed to the prenatal steroid $(p=0.498)$. B) Primiparity and multiparity $(p=0.216)$. C) Maternal age of less than 35 years and 35 years or older $(p=0.704)$

In the late preterm group, the relationship between neonatal hypoglycaemia and exposure may be more frequent, as reported by Gyamfi-Bannerman et al. in 2016. Recent recommendations of the American College of Obstetricians and Gynaecologists, regarding the application of steroids for lung maturation in this group of neonates, or, as another publication proposes, in late preterm infants with a high risk of morbidity and mortality, may be controversial because this measure has been associated with possible short-term complications such as hypoglycaemia and subsequent neurological alterations [29, 30]. Alrais et al. reported a higher risk of hypoglycaemia in late preterm infants and indicated higher admission to the neonatal intensive care unit secondary to low glucose values, but with no significant difference between the length of stay [22]. Vaibhavi reported in his retrospective cohort study higher rates of hypoglycaemia and hyperbilirubinaemia in late preterms in whom the steroid was not applied according to the exact criteria of the American College of Obstetricians and Gynaecologists (single pregnancy, is likely to 
remain pregnant 12 hours, no previous treatment with steroids, no pregestational diabetes, no signs of infection or other contraindications) [31]. Prospective studies are necessary to clarify the association between this exposure and hypoglycaemia.

The time for the appearance of hypoglycaemia is variable; Stark et al. report that 50\% of hypoglycaemia in neonates with risks factors occurs between the first 2 hours and 20 minutes of life [25]. However, it would be necessary to analyse these data cautiously because it has been described that the physiological nadir in preterm and term neonates occurs in the first three hours of life [32]. In our case, the speed of onset was greater in the first 8.8 hours of life, which became more evident when adjusting the variable for maternal age and primiparity. This result had already been documented by Pettit et al. who reported a higher risk of presenting hypoglycaemia (OR 1.60, 95\% Cl: 1.24-2.07) when the variables were adjusted for gestational age, maternal age of 35 years, nulliparity, race, and diabetes [24]; however, more studies are needed to define their association.

We recognise that one of the weaknesses of the study is the size of the sample of the cohorts, which could explain the absence of differences in the incidences. Despite this, the characteristics of the population were similar, thereby making the information obtained relevant, although a larger sample might be needed to show statistically significant differences.

\section{References}

1. Van Haltren K, Malhotra A. Characteristics of infants admitted with hypoglycemia to a neonatal unit. J Pediatr Endocrinol Metab 2013; 26: 525-529. doi: 10.1515/jpem-2013-0009

2. McKinlay CJ, Alsweiler JM, Ansell JM, et al. Neonatal Glycemia and Neurodevelopmental Outcomes at 2 Years. N Engl J Med 2015; 373: 1507-1518. doi: 10.1056/NEJMoa1504909

3. Adamkin DH. Neonatal hypoglycemia. Indian J Pediatr 2017; 22 : 36-41. doi: 10.1016/j.siny.2016.08.007

4. Afzal M, Afzal AG, Wahab A. Glucose levels in late preterm and term newborns at one hour of life and frequency of hypoglycemia. Pakistan Armed Forces Medical Journal 2015; 65: 506-510.

5. Rozance PJ, Hay WW. New approaches to management of neonatal hypoglycemia. Matern Health Neonatol Perinatol 2016; 2: 3. doi: 10.1186/s40748-016-0031-z

6. Rozance PJ, Wolfsdorf Jl. Hypoglycemia in the Newborn. Pediatr Clin North Am 2019; 66: 333-342. doi: 10.1016/j.pcl.2018.12.004

7. Thornton PS, Stanley CA, De Leon DD, et al. Recommendations from the Pediatric Endocrine Society for Evaluation and Management of Persistent Hypoglycemia in Neonates, Infants, and Children. J Pediatr 2015; 167: 238-245. doi: 10.1016/j.jpeds.2015.03.057

8. Adamkin DH. Metabolic Screening and Postnatal Glucose Homeostasis in the Newborn. Pediatr Clin North Am 2015; 62: 385-409. doi: 10.1016/j.pcl.2014.11.004

9. Committee on Fetus and Newborn, Adamkin DH. Postnatal Glucose Homeostasis in Late-Preterm and Term Infants Clinical Report. Pediatrics 2011; 127: 575-579. 10.1542/peds.2010-3851

\section{Conclusions}

There are no significant differences in the incidence of hypoglycaemia between infants exposed in utero to steroids for lung maturation and those not exposed between week 26 and 34 of gestational age. Although the incidence of hypoglycaemia is similar to the values previously reported in the literature, efforts must be made to reduce it, due to the long-term neurological impact of this condition.

More studies are needed to clarify the aetiological relationship between exposure to antenatal steroids for lung maturation and neonatal hypoglycaemia. Despite differences in results, the positive impact on neonatal mortality and morbidity with the use of the steroids cannot be denied. By studying this relationship, we intend to reinforce the importance of identifying risk factors and controlling glycaemic values in this population in order to take timely measures to avoid it.

\section{Acknowledgement}

The authors highlight the contribution of professor Luis Alfonso Díaz Martínez. MD, Pediatrician and MSc Epidemiology of Industrial University of Santander.

10. Thompson-Branch A, Havranek T. Neonatal Hypoglycemia. Pediatr Rev 2017; 38: 147-157. doi: 10.1542/pir.2016-0063

11. Morag I, Okrent AL, Strauss T, et al. Early neonatal morbidities and associated modifiable and non-modifiable risk factors in a cohort of infants born at 34-35 weeks of gestation. ISRN Obs Gynecol 2014; 7058: 1-7.

12. Puchalski ML, Russell TL, Karslen KA. Neonatal Hypoglycemia Is There a Sweet Spot? Crit Care Nurs Clin NA 2018; 30: 467-480.

13. Stanley CA, Rozance PJ, Thornton PS, et al. Re-evaluating "transitional neonatal hypoglycemia": Mechanism and implications for management. J Pediatr 2015; 166: 1520-1525.e1.

14. Bromiker R, Perry A, Kasirer Y, et al. Early neonatal hypoglycemia: incidence of and risk factors. A cohort study using universal point of care screening. I Med. 2019; 32: 786-792. doi: 10.1080/ 14767058.2017.1391781

15. Bevilacqua E, Brunelli R, Anceschi MM. Review and meta-analysis: Benefits and risks of multiple courses of antenatal corticosteroids. J Matern Fetal Neonatal Med 2010; 23: 244-260. doi: 10.1080/14767050903165222

16. Mazumder P, Dutta S, Kaur J, et al. Single versus multiple courses of antenatal betamethasone and neonatal outcome: a randomized controlled trial. Indian Pediatr 2008;45: 661-667.

17. Romejko-Wolniewicz E, Oleszczuk L, Zaręba-Szczudlik J, et al. Dosage regimen of antenatal steroids prior to preterm delivery and effects on maternal and neonatal outcomes. J Matern Fetal Neonatal Med 2013; 26: 237-241. doi: 10.3109/14767058.2012.733758

18. Abbasi S, Hirsch D, Davis J, et al. Effect of single versus multiple courses of antenatal corticosteroids on maternal and neonatal outcome. Am J Obstet Gynecol 2000;182:1243-1249. 
19. Elimian A, Figueroa R, Spitzer AR, et al. Antenatal corticosteroids: Are incomplete courses beneficial? Obstet Gynecol 2003; 102: 352-355. doi: 10.1016/s0029-7844(03)00485-x

20. Crowther CA, McKinlay CJ, Middleton P, et al. Repeat doses of prenatal corticosteroids for women at risk of preterm birth for improving neonatal health outcomes. Cochrane Database Syst Rev 2011; (6): CD003935. doi: 10.1002/14651858.CD003935.pub3

21. Gyamfi-Bannerman C, Thom EA, Blackwell SC, et al. Antenatal Betamethasone for Women at Risk for Late Preterm Delivery. N Engl J Med 2016; 374: 1311-1320. doi: 10.1056/NEJMoa1516783

22. Alrais MA. Frequency of Neonatal Hypoglycemia After Implementation of Antenatal Late Preterm Steroids Use. Obstet Gynecol 2018; 131: 124S.

23. Koivisto M, Peltoniemi OM, Saarela T, et al. Blood glucose level in preterm infants after antenatal exposure to glucocorticoid. Acta Paediatr Int J Paediatr 2007; 96: 664-668. doi: 10.1111/j.16512227.2007.00242.x

24. Pettit KE, Tran SH, Lee E, Caughey AB. The association of antenatal corticosteroids with neonatal hypoglycemia and hyperbilirubinemia. J Matern Fetal Neonatal Med 2014; 27: 683-686. doi: 10.3109/14767058.2013.832750

25. Stark J, Simma B, Blassnig-ezeh A. Incidence of hypoglycemia in newborn infants identified as at risk. J Matern Neonatal Med 2019; 0: 1-6. doi: 10.1080/14767058.2019.1568985.
26. Hosagasi NH, Aydin M, Zenciroglu A, et al. Incidence of hypoglycemia in newborns at risk and an audit of the 2011 American academy of pediatrics guideline for hypoglycemia. Pediatr Neonatol 2018; 59: 368-374. doi: 10.1016/j.pedneo.2017.11.009.

27. Harding JE, Harris DL, Hegarty JE, et al. An emerging evidence base for the management of neonatal hypoglycaemia. Early Hum Dev 2017; 104: 51-56. doi: 10.1016/j.earlhumdev.2016.12.009.

28. Alsweiler JM, Gomes L, Nagy T, et al. Adherence to neonatal hypoglycaemia guidelines: A retrospective cohort study. J Paediatr Child Health 2019; 1-7. doi: 10.1111/jpc.14544

29. Borders AE. Gyamfi-bannerman C. Antenatal Corticosteroid Therapy for Fetal Maturation. Obstet Gynecol 2018; 130: 102-109. doi: 10.1097/AOG.0000000000002237

30. Haviv HR, Said J, Mol BW. The place of antenatal corticosteroids in late preterm and early term births. Semin Fetal Neonatal Med 2019; 24: 37-42. doi: 10.1016/j.siny.2018.10.001

31. Vaibhabi U. Evaluating Practice Patterns of Late Preterm Antenatal Steroid Administration and Adherence to Recommendations. Obstet Gynecol 2019; 133: 119S-120S.

32. Kaiser JR, Sasha B, Rozance PJ. Newborn Plasma Glucose Concentration Nadirs by Gestational-Age Group. Neonatology 2018; 113: 353-359. 